\title{
SUSTAINABLE URBAN DRAINAGE APPROACH, FOCUSING ON LID TECHNIQUES, APPLIED TO THE DESIGN OF NEW HOUSING SUBDIVISIONS IN THE CONTEXT OF A GROWING CITY
}

\author{
M.G. MIGUEZ, J.M. BAHIENSE, O.M. REZENDE \& A.P. VERÓL \\ Universidade Federal do Rio de Janeiro, Brazil.
}

\begin{abstract}
City growth must be carefully planned, in order to deal with the relevant hydrological changes, caused by urbanisation effects. Frequently, the increasing of the impervious surface areas is the major cause of urban floods aggravation. For this reason, new urban drainage design concepts have been researched in the recent decades, looking for a more sustainable stormwater management approach. The concept of sustainability in urban drainage implies that floods may not be transferred to downstream and that drainage systems must be planned considering urban development along time. Storage and infiltration measures, distributed over the watershed and integrated with urban landscape, should be introduced to reduce flood peaks and reorganise flood flow patterns. Following this path, the concept of low impact development (LID) may be a reference for urban drainage projects of new housing subdivisions. This concept tends to produce built environments with minor hydrological changes, trying to preserve or recover natural flow conditions prior to the urbanisation. In this context, this paper aims to discuss the problems related to urban flood in a conceptual, but practical, perspective, comparing different alternatives of drainage design for urban areas in a development process. In particular, a case study in the neighbourhood of Guaratiba, at Rio de Janeiro City, Brazil, will be developed. This region is under an increasing urban growth pressure, but it is still possible to plan and design an alternative occupation. Basically, two approaches were compared: a traditional end of pipe design concept and an alternative sustainable design approach, based on the LID concept. The effects of the LID flood control measures were analysed and compared, applied in both public and private areas of a new urban subdivision project. A critical storm event was considered for the local scale and for Cabuçu River, which is the receiving water body for the local drainage system. The combined use of infiltration and storage measures was able to recover flood peaks. The pre-urbanisation values were approximately reproduced, both for the local and the basin scales, although peak times were not recovered.

Keywords: low impact development, urban site development, sustainable urban drainage, flood control, mathematical modelling
\end{abstract}

\section{INTRODUCTION}

Urban planning integrates some fundamental elements such as sanitation, transport, housing, entertainment, culture, education and health, among others. Thus, it can be said that sustainability of urban areas depends on several interconnected aspects, composing a complex and multidisciplinary framework. One important element in this framework is the urban drainage system.

The relation between urban development and urban drainage is very close. Urbanisation can lead to important hydrologic and environmental modifications [1]. The removal of natural vegetation, followed by the paving of large surface areas, causes heavy changes in the natural hydrologic cycle. The main consequences refer to the increase of peak discharges, volumes, flow velocities and frequency of floods. In the opposite way, infiltration and local storage capacity are reduced. Consequently, the resulting floods can greatly affect urban infrastructure, in general, and degrade urban environment and city quality of life.

Over decades, canalisation was considered the most common and effective intervention to control flood levels and peak discharges, without concerns about the transference of flood risk to other areas 
or even the mitigation of flood causes [2]. However, since the 1970s, the traditional approach for urban drainage systems design started to be perceived as unsustainable [3], as its conception tends to accelerate, increase and transfer peak discharges. In addition, it is possible to say that changes in the hydrological cycle, induced by traditional flood control measures, could bring negative consequences, which are summarised by Baptista et al. [4] in three aspects:

- Economic: By transferring flood to downstream areas, leading to constant expansion works in drainage systems, which generates additional costs in a city budget.

- Social: Population lose flood risk perception, through an unreal sense of security (brought by the traditional works) that may lead to significant losses to the society, when the drainage system fails.

- Environmental: Present and future uses of water in urban environment for other purposes become compromised and limited.

As an alternative to the traditional concept, several measures started to be developed intending to compensate for the urban growth changes in the water cycle. The use of water-sensitive design approaches, sustainable drainage systems and low impact development (LID) technologies can contribute with the minimisation of watershed hydrology impacts caused by the urbanisation [5,6]. The concept of low impact development - LID [5,7] arose in the USA, considering the principles based on the stormwater source control, by the use of microscale measures distributed throughout the watershed [5]. LID techniques seek to produce built environments with minor hydrological changes, trying to recover natural conditions. Besides, LID practices offer an additional benefit as they can be integrated into the urban infrastructure being designed as recreational areas in dry weather. In this situation, they assume the characteristics of multifunctional landscapes [8]. They are more aesthetically pleasing than traditional, structural stormwater conveyance systems [5]. This approach constitutes an alternative for a sustainable urban drainage system. Drainage solutions need to be developed in an integrated way, considering the basin as the basic unit of planning and design but also concerning socio-economic and environmental aspects. Some recent studies $[9,10]$ presented positive results from the use of LID measures in the runoff control, especially for small and moderate rainfall events. Hood et al. [10] also detach that LID practices on a larger scale can greatly reduce the impact of land development.

In this context, this paper aims to discuss urban flood problems, starting from a conceptual perspective and evolving to a practical design proposition, intending to compare different possibilities for developing a new urban site, departing from the housing subdivision scale assessment, and also concerning its interaction with the watershed scale. A case study at a yet non-urbanised area in the neighbourhood of Guaratiba, located in the West Zone of Rio de Janeiro City, Brazil, is developed to support the discussions. This region is under an increasing urban growth pressure and it is still possible to plan an alternative occupation. Different possibilities for urban development are compared, considering two approaches for the urban drainage system design: a traditional solution and a sustainable design approach, based on LID concepts. Thus, the effects of different flood control measures, applied to both public and private areas of a projected housing subdivision, are analysed and compared. The rainfall design event will be considered with return periods (RP) of 10 and 25 years. These values of RP refer to the recommendation of the Municipality for the minor and major drainage design. It is expected that a more sustainable approach, based on LID interventions, leads to a more effective minor-drainage system design. Besides, it is estimated that an improvement occurs on the major-drainage system operation, providing positive results for the entire city tissue inside the considered watershed. 


\section{SUSTAINABLE URBAN DRAINAGE AND LOW IMPACT DEVELOPMENT}

Sustainable urban drainage systems have a straight relation with city development, mainly associated with urban land use planning. The basic principles of sustainable drainage system take into account the possibility of introducing minimum changes in local hydrological cycle, in order to favour the maintenance of natural flow patterns. Some techniques, based on storage and infiltration measures, such as retention basins, detention ponds, infiltration trenches, green roofs and permeable pavements, should be considered on the planning of new urban areas. These measures can also be applied at consolidated urban areas, although with some difficulties, in order to minimise the negative effects of an unplanned city development.

Sustainable technical solutions for urban drainage can be grouped according to their position in the drainage system: source control measures, local control measures, slow transport measures or downstream control measures [11], as schematically shown in Fig. 1.

The concept of LID stands up for the use of techniques that could be able to increase the local capacity of intercepting, infiltrating and evaporating stormwaters, and also increasing storage opportunities and delaying the runoff generated by urbanisation, in a way as similar as possible to the natural behaviour [12]. Several studies consider LID techniques as best management practices articulated to reduce runoff and improve water quality [13-15].

According the USDoD Manual [16], a LID project should follow some basic principles, such as:

- Conserve natural drainage pathways, through the preservation of soil and vegetation conditions prior to urbanisation and the minimisation of impervious surfaces.

- Use of the natural capacity of infiltration and treatment of stormwater in vegetated areas, also promoting the groundwater recharge.

- Respect natural aspects of the site, avoiding standardisations in project elaboration.

- Reduce the impacts of development on hydrologic cycle, establishing compensatory measures for stormwaters management to reduce additional runoff generation.

The sustainable approach coupled with LID concepts leads to a promising possibility for stormwater management, designed to maintain the watershed natural flow characteristics prior to the city construction [17].

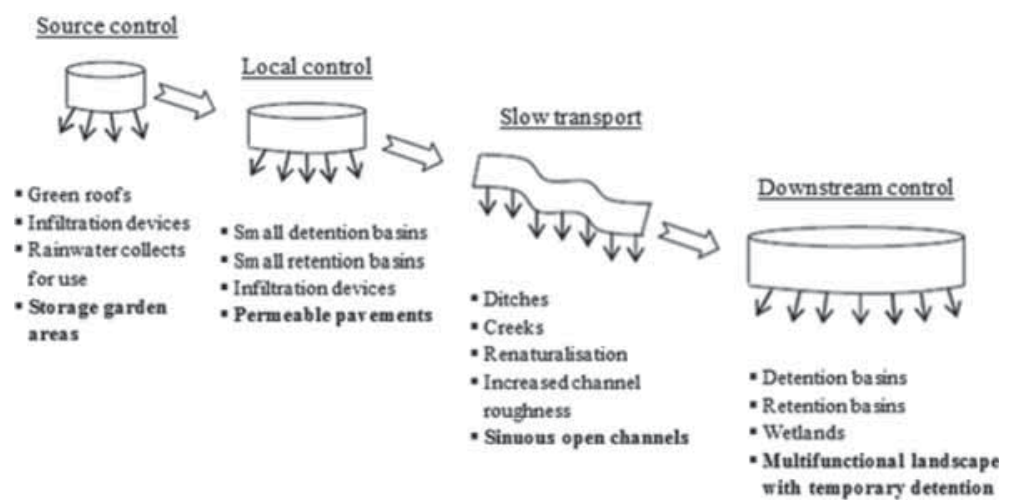

Figure 1: Classification of sustainable technical solutions according to their location in the drainage system (adapted from Stahre [11]). 


\section{CASE STUDY: A NEW HOUSING SUBDIVISION PROJECT AT GUARATIBA NEIGHBOURHOOD, IN RIO DE JANEIRO CITY}

A new housing subdivision project is proposed in an urban development area, in the city of Rio de Janeiro, Brazil [18]. Located at Guaratiba neighbourhood, in the West Zone of the city, the chosen site occupies a riverine area, on Cabuçu River basin, as shown in Figs 2 and 3. The total area of this new housing subdivision sums up to $350,000 \mathrm{~m}^{2}$.

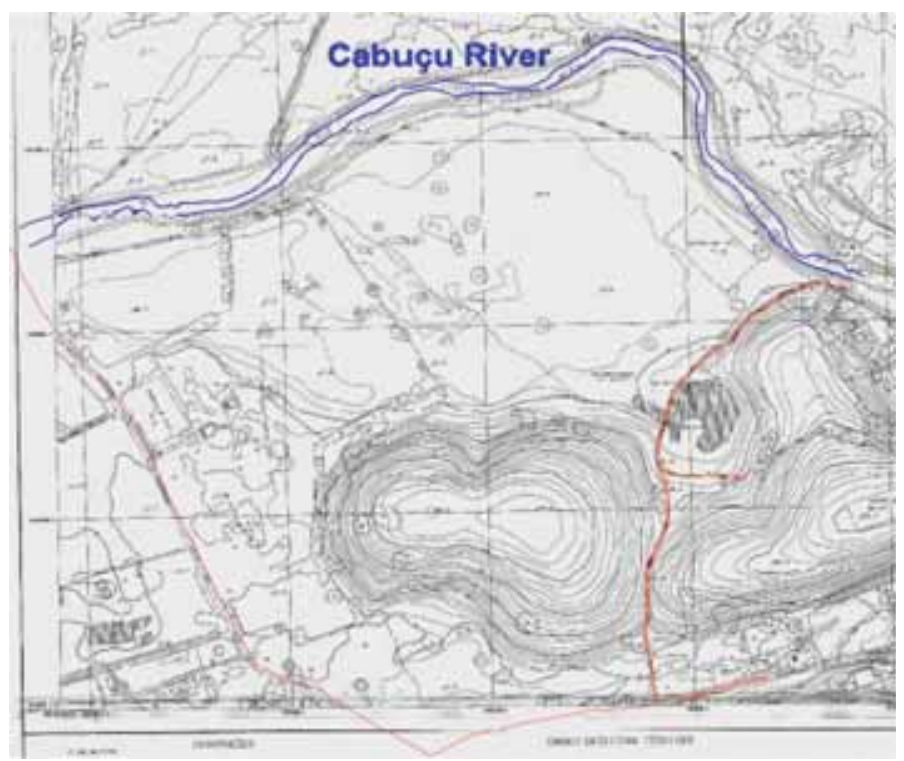

Figure 2: Plain view of the case study area.

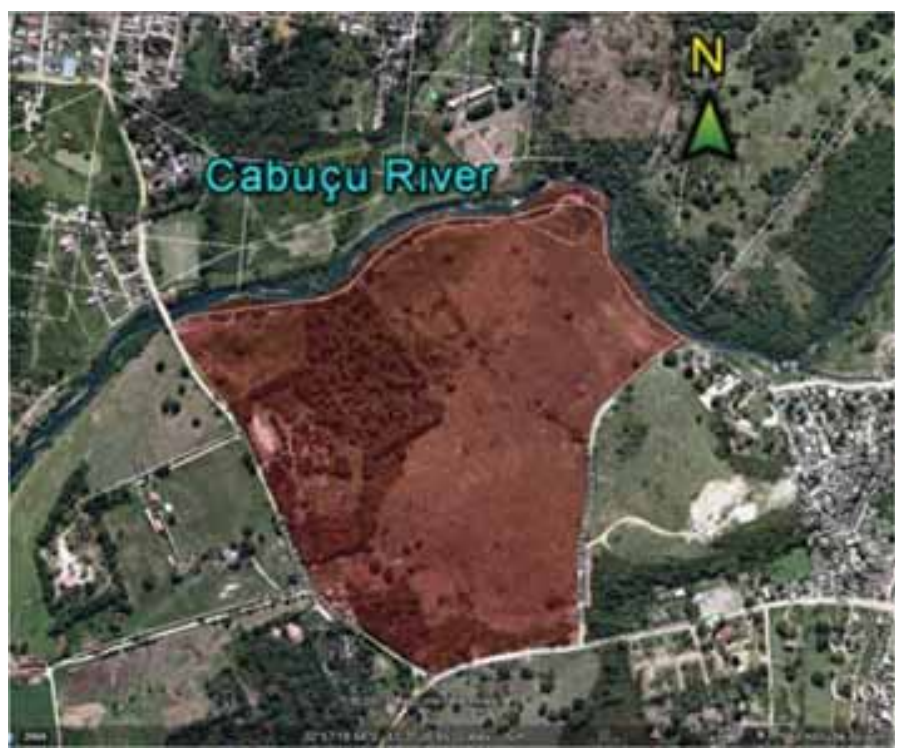

Figure 3: Aerial view of the case study area [19]. 


\subsection{Proposed scenarios comparison}

The basic scenario, taken as the starting point for the present discussion, was related with the natural runoff produced in the pre-development situation. After characterising the natural flow patterns, the first design scenario considered a traditional drainage system project, focusing on canalisation concepts and discharging directly into Cabuçu River, as shown in Fig. 4. Both scenarios are used for comparison purposes with the sustainable alternatives.

Then, in the sequence, it was proposed a drainage system based on the LID approach. More specifically, this project conception considered four types of measures, detailed as follows and applied both individually and jointly.

- Lowering of lot yard areas: All lots had their yard areas lowered $10 \mathrm{~cm}$, in order to receive the contribution from roof tops and other impervious areas (Fig. 5). According to the municipal legislation, a maximum of $50 \%$ of each lot total area could be destined for construction. Also, at least half of the non-constructed area should have a pervious surface. Thus, for simulation purposes, rain gardens were considered occupying the yard areas. They were assumed as $25 \%$ of each lot total area. The stored volume was supposed to infiltrate along time and only exceeding waters should be conducted to the drainage net. In this case, rain gardens are combined with the strategy of lowering ground levels to produce a temporary storage capacity and also favour infiltration.

- Permeable pavements: Sidewalks and parking areas were planned to receive permeable pavements, which allow stormwater to drain through them into gravel reservoirs of $40-\mathrm{cm}$ height (Fig. 6). These reservoirs were connected to the drainage net through small orifices, enabling a temporary storage and a damping effect. They may also receive the contribution of the surrounding impervious areas.

- Sinuous open channel in green alleys: The central green alleys located on the flattest part of the housing subdivision area were used as temporary storage measures and also to increase flow paths (Fig. 7). These alleys, with $10-\mathrm{m}$ width, have received a sinuous channel approximately $50 \%$ longer than the original pipe of the traditional design. They also had their ground elevation lowered, conforming a trapezoidal reservoir.

- Multifunctional landscape: The central square, originally designed for landscaping and also as a public leisure area, was proposed as a temporary detention pond, in a multifunctional landscape configuration.

\subsection{Hydrology}

Two different scales are important in designing a new urban expansion: the local scale, which refers to the operation of the minor drainage, guaranteeing that the streets, and even the lots, will not be flooded by the runoff; and the major drainage scale, which receives the contribution of the new housing subdivision area, possibly increasing floods downstream. In this context, these two conditions were considered in the modelling process. In Rio de Janeiro City, the RP considered for the minor drainage design is 10 years. For the major drainage design, a RP of 25 years is used.

The calculated concentration time for the Cabuçu River basin at the housing subdivision area was estimated in $230 \mathrm{~min}$. For the local housing subdivision catchment, this estimated time was approximately $38 \mathrm{~min}$. Both the estimations were made using the Kirpich formula. The design rainfall was based on a local intensity-duration-frequency equation, temporally distributed through the alternating block method, dividing the total rainfall time, defined as $230 \mathrm{~min}$, in blocks of $10 \mathrm{~min}$, as shown in 


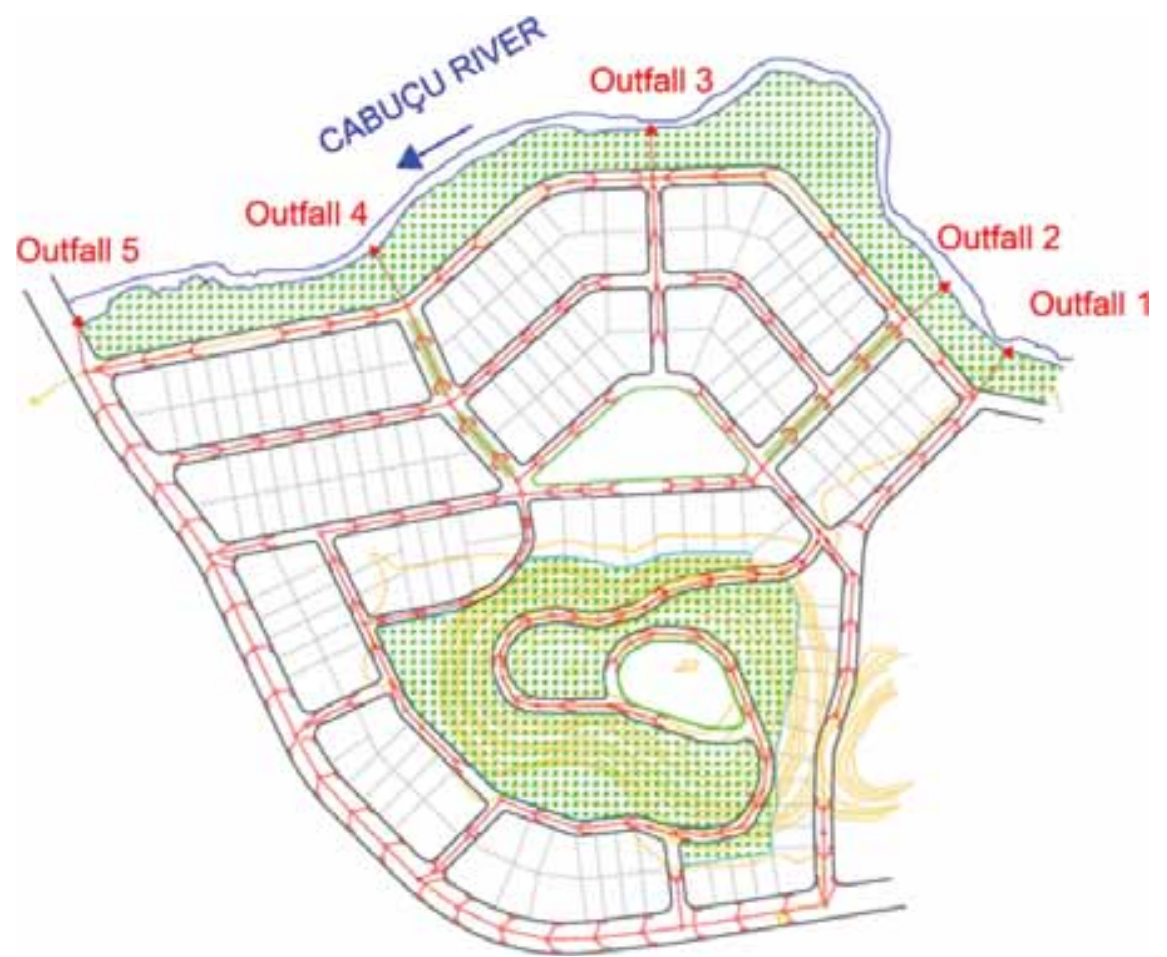

Figure 4: Traditional drainage system designed for the new housing subdivision area.

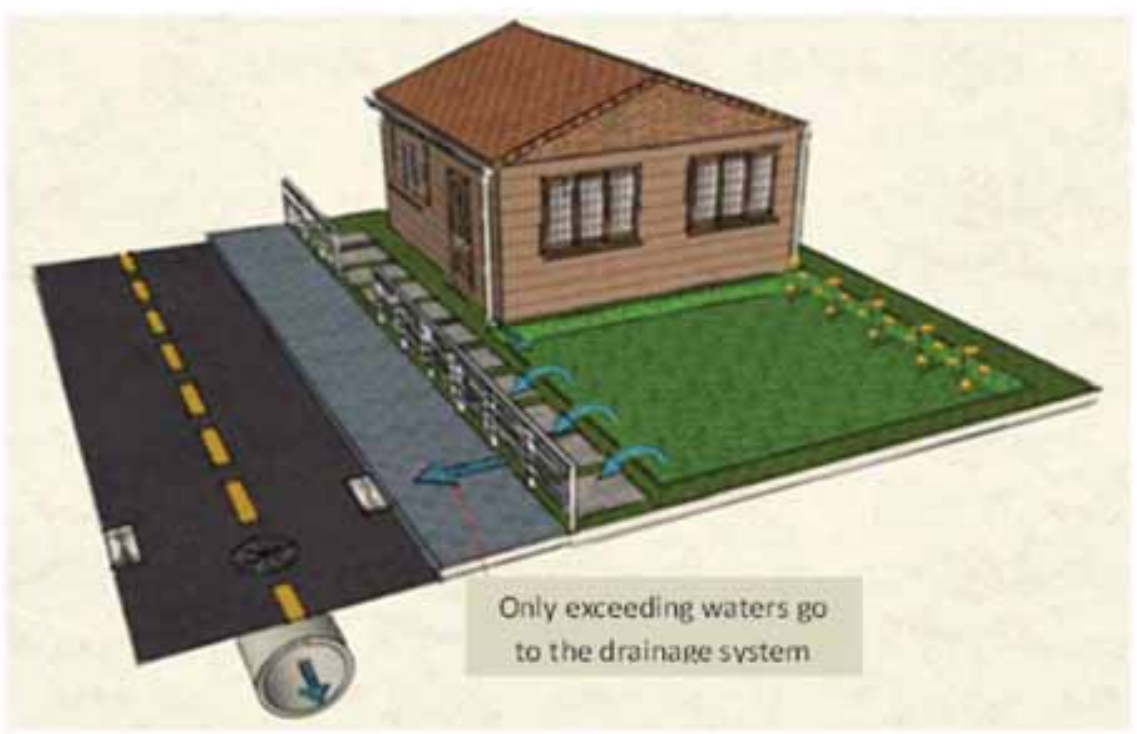

Figure 5: Lots occupation considering a storage and infiltration capacity in the garden area disconnection from the formal drainage system. 


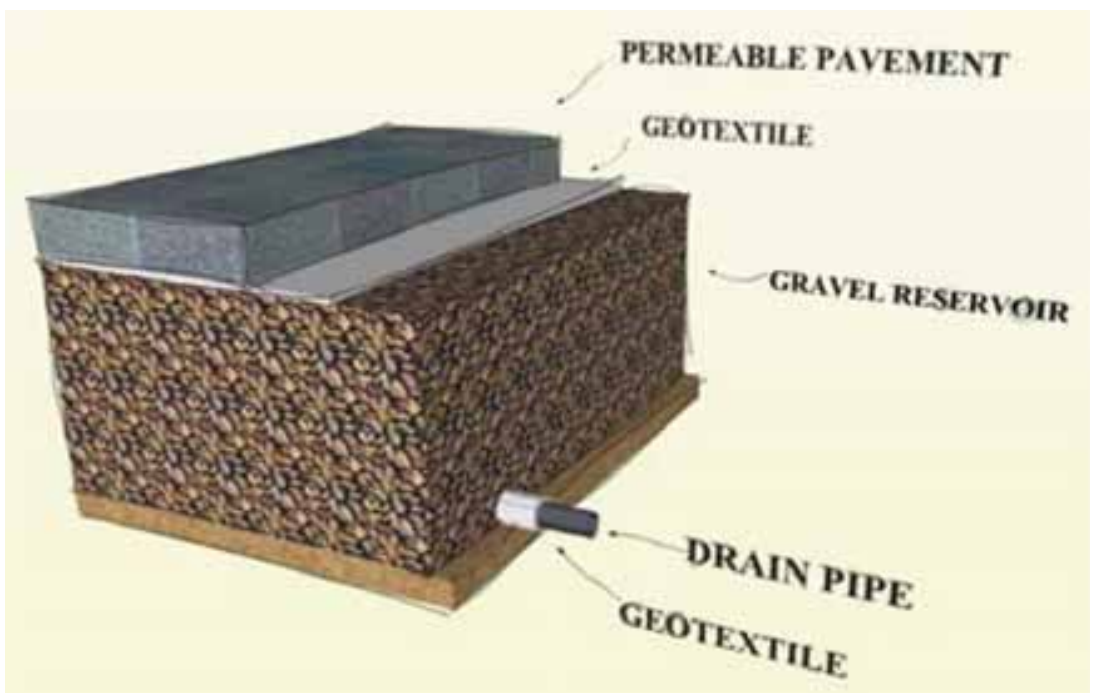

Figure 6: Permeable pavements applied to sidewalks and parking areas as a temporary storage of water in gravel reservoirs.

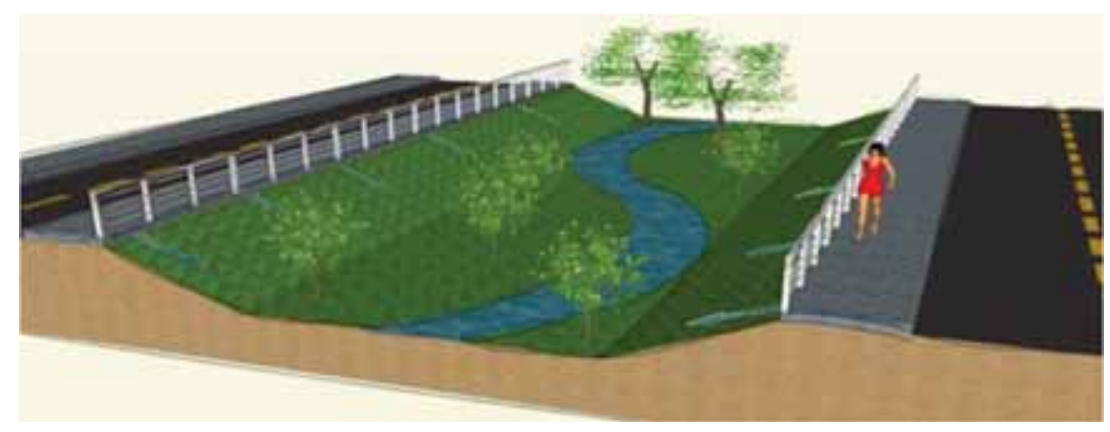

Figure 7: Sinuous channel in a green alley as an alternative to the traditional pipes.

Fig. 8. This strategy allows the evaluation of the drainage system responses under critical rainfall conditions for the Cabuçu River basin and the housing subdivision site. The total event is critical for the Cabuçu River basin, but the local critical event is contained inside the basin critical event. The four central major rainfall blocks (totalising $40 \mathrm{~min}$ ) are critical at local scale.

The effective rainfall is obtained by the application of a simple rational method, distributed over the watershed, considering individually each lot, street stretches and open spaces. The distributed results of this rainfall-runoff transformation are routed with a hydrodynamic mathematical model, called MODCEL [20,21]. This model was conceived to mainly simulate urban watersheds subject to flooding events and it is able to integrate the runoff generation and the superficial flow processes with the drainage net system. For practical purposes of comparison, MODCEL was used as a computational support. The main runoff coefficients applied are shown in Table 1. The Manning coefficients used in hydrodynamic routing were 0.013 in pipe links and 0.06 in street links. 


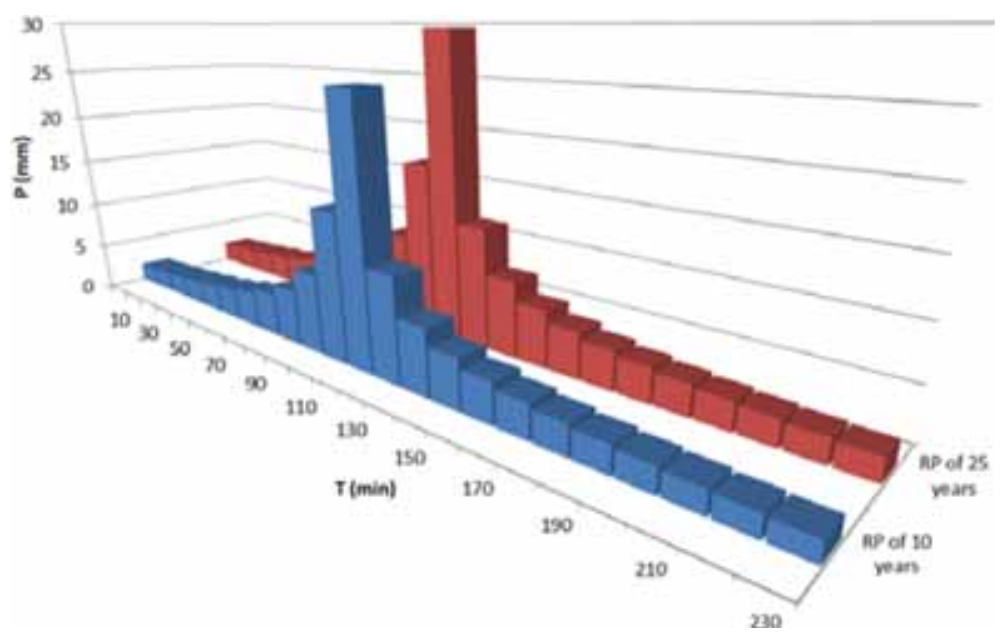

Figure 8: Design rainfalls for RPs of 10 and 25 years.

Table 1: Runoff coefficients.

\begin{tabular}{|c|c|c|c|c|c|}
\hline \multicolumn{3}{|c|}{ Lots } & \multirow{2}{*}{ Streets } & \multirow{2}{*}{$\begin{array}{l}\text { Vegetated } \\
\text { riverine areas }\end{array}$} & \multirow{2}{*}{$\begin{array}{l}\text { Vegetated } \\
\text { slopes }\end{array}$} \\
\hline $\begin{array}{l}\text { Impervious } \\
\text { area }(75 \%)\end{array}$ & Pervious area $(25 \%)$ & Average & & & \\
\hline 0.80 & 0.15 & 0.64 & 0.95 & 0.30 & 0.35 \\
\hline
\end{tabular}

\section{RESULTS AND DISCUSSION}

\subsection{Individual evaluation of the proposed LID measures}

The complete set of LID measures introduced in the drainage system of the studied area is shown in Fig. 9.

Initially, the results of three scenarios were individually analysed and compared with the ones obtained for the traditional drainage system design:

- Scenario 1: Lowering the garden areas in each lot.

- Scenario 2: Permeable pavements on sidewalks and parking areas.

- Scenario 3: Central square working as temporary detention pond and sinuous channels in two green alleys, also allowing a temporary storage.

The main goal of this set of simulations was to evaluate the individual effects of LID measures in the minor drainage system. In this case, it was considered the RP of 10 years.

Table 2 shows the maximum discharges at the end of each drainage network system, which outfalls into five different points of Cabuçu River, as it can be seen in Fig. 4. Scenarios 1 and 2 are plotted in this table. Scenario 3 will be discussed in sequence. Both Scenarios 1 and 2 presented a 


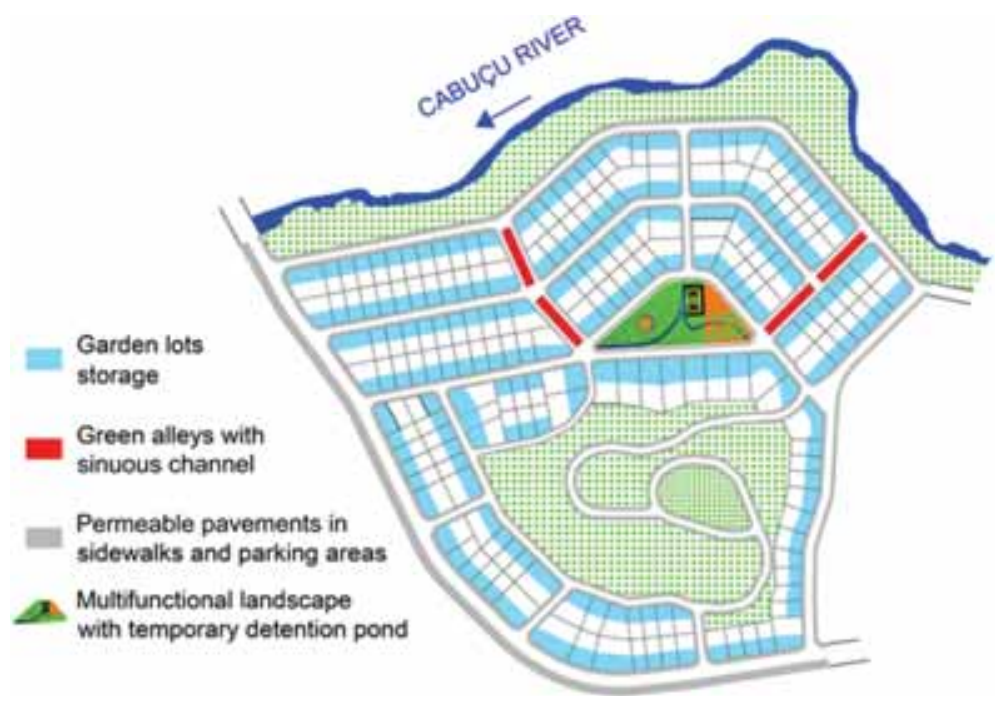

Figure 9: LID interventions applied to the designed drainage system.

Table 2: Maximum discharges at the drainage system outfalls for a rainfall with RP 10 years.

\begin{tabular}{lccc}
\hline \multirow{2}{*}{ Drainage net } & \multicolumn{3}{c}{ Maximum discharges $\left(\mathrm{m}^{3} / \mathrm{s}\right)$} \\
\cline { 2 - 4 } & Traditional project & Scenario 1 & Scenario 2 \\
\hline 1 & 2.05 & 1.78 & 0.88 \\
2 & 2.55 & 1.81 & 1.79 \\
3 & 0.47 & 0.39 & 0.37 \\
4 & 1.62 & 1.21 & 1.16 \\
5 & 0.16 & 0.10 & 0.08 \\
\hline
\end{tabular}

reduction in the outfall peak flows, as shown by Fig. 10. It can also be verified a reduction in the total discharged volume for Scenario 1, due to the infiltration effect.

Scenario 3 has the drainage nets 2 and 4 diverted to the central housing subdivision square. This square, used as a temporary detention pond, was connected with Cabuçu River through the drainage net 3. On the downstream reaches of drainage nets 2 and 4, after their diversion to the square, sinuous channels were implemented at two green alleys of $10-\mathrm{m}$ wide, with the aim of increasing flow paths and allowing a complementary storage capacity. Figure 11 shows the outfall of the drainage net 3 . This drainage net, as expected, had an increase in the peak discharge. The outfall hydrographs of drainage nets 2 and 4 are shown in Figs 12 and 13, where it can be observed a reduction of up to $60 \%$ in peak flows, when compared with the traditional design. Considering this set of propositions, these three outfalls presented discharges of similar magnitude. The behaviour of drainage nets 1 and 5, which were not affected by the proposed measures, did not show any significant changes. 


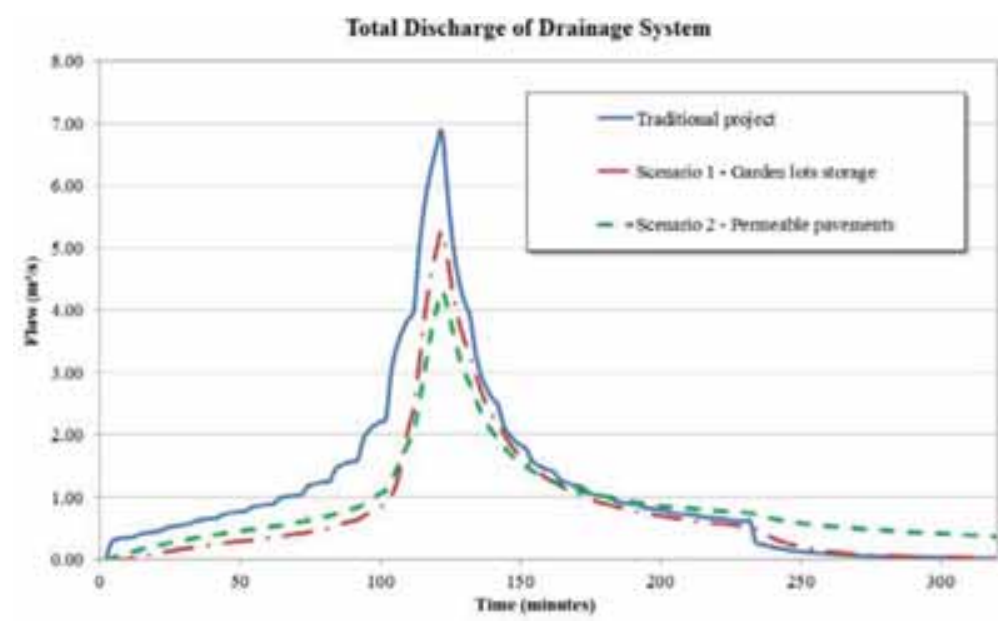

Figure 10: Total discharge of drainage system, for the 10 years rainfall.

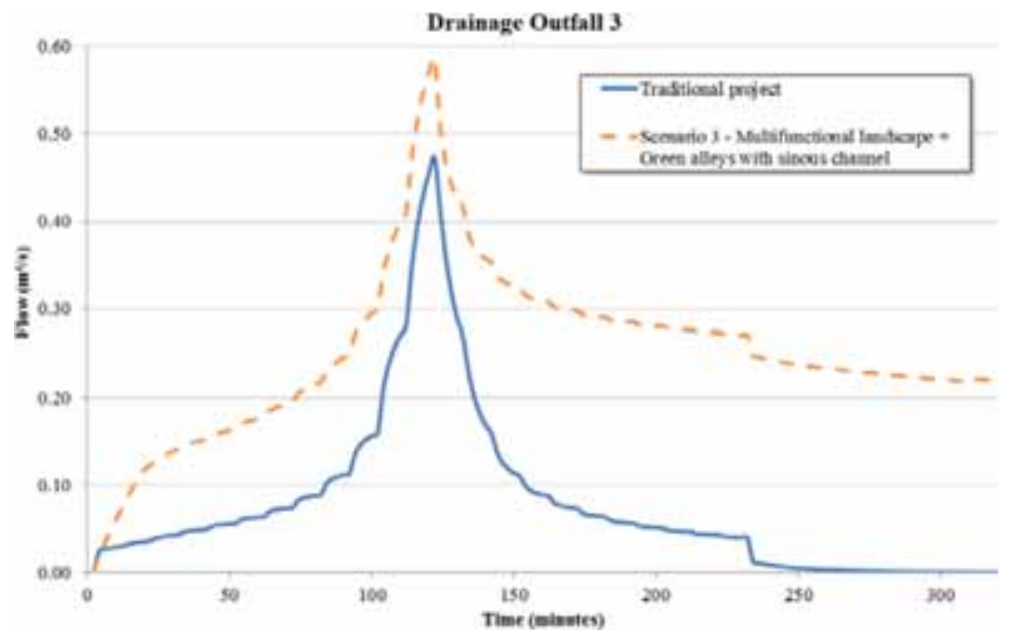

Figure 11: Drainage outfall 3, for the 10 years rainfall.

\subsection{Joint evaluation of the proposed LID measures}

After the individual analysis of the proposed LID measures, the previous scenarios were re-combined into two new scenarios, numbered as 4 and 5, according to the way they operate in the urban tissue. In addition, a sixth scenario was simulated to evaluate the effect of private and public actions working together.

- Scenario 4: Private actions that correspond to measures whose responsibility of implementation refers to the owner of the lot, because they are applied at private areas. This is the case of lowering the garden areas inside the lots (equivalent to Scenario 1). 


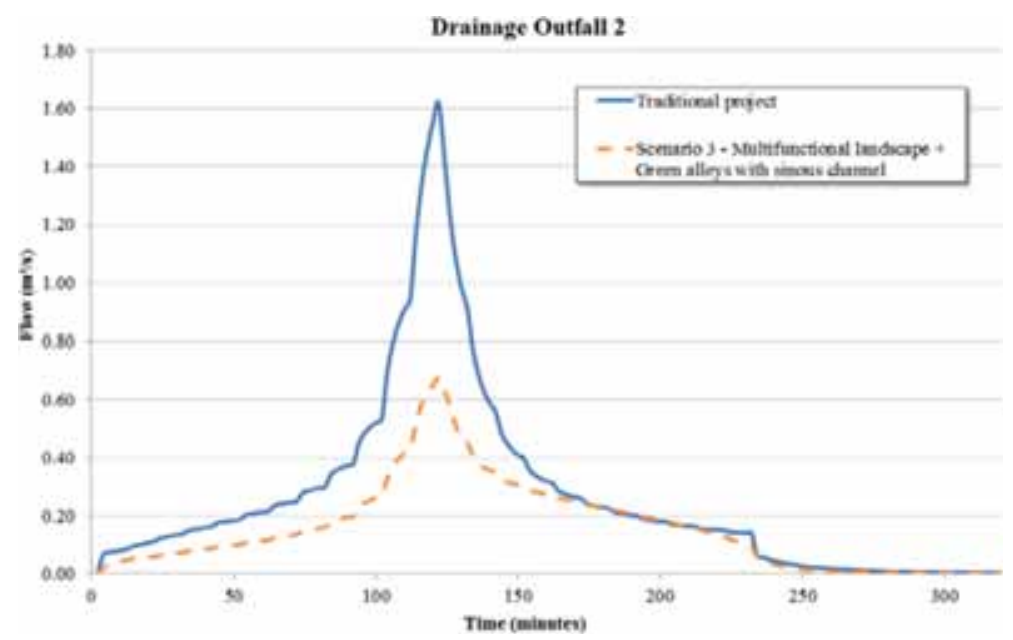

Figure 12: Drainage outfall 2, for the 10 years rainfall.

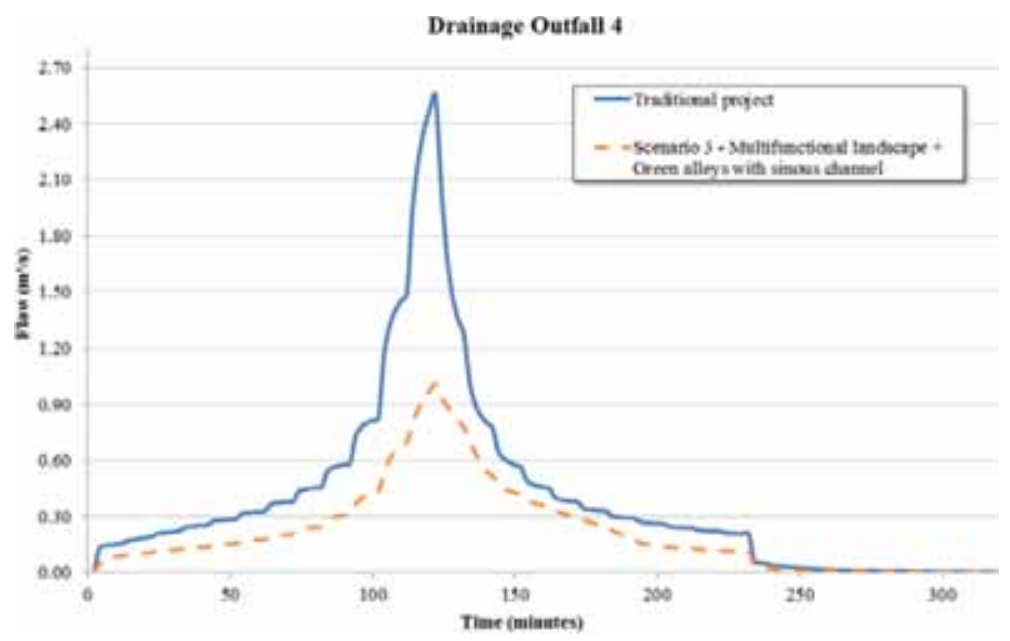

Figure 13: Drainage OUTFALL 4, for the 10 years rainfall.

- Scenario 5: Public actions that correspond to measures implemented only in the public areas, under the responsibility of the municipality. This case corresponds to the permeable pavements on sidewalks and parking areas and the use of the central square as a temporary detention reservoir, complemented by the sinuous channels applied to the green alleys (Scenario $2+$ Scenario 3 ).

- Scenario 6: Private and public actions combined that correspond to the combination of scenarios 4 and 5.

The sum of the five drainage net discharges that compose the housing subdivision drainage system, for Scenarios 4 and 5, is shown in Fig. 14, considering the critical rainfall event for local scale (RP 10 years). As the goal of LID is to reduce the urban development impact on the hydrological cycle, 
it is also presented the local pre-urbanisation hydrograph for this rainfall event, as well as the results for the traditional design.

Analysing the hydrographs shown in Fig. 14, it is possible to notice the increase in magnitude of peak flow, varying from $2.14 \mathrm{~m}^{3} / \mathrm{s}$ in pre-urbanised scenario to $6.87 \mathrm{~m}^{3} / \mathrm{s}$ after the implementation of the traditional drainage design. A reduction in the peak time is also noticeable, after the new urban development. It can be observed that the application of LID measures in urban design reduces the peak flow to $2.93 \mathrm{~m}^{3} / \mathrm{s}$, about $57 \%$ less than the traditional design, when considering the public actions, and to $5.24 \mathrm{~m}^{3} / \mathrm{s}$, about $24 \%$ less than the traditional design, when considering the private actions. These peak flows show a reduced impact on the hydrological cycle, when compared with traditional drainage system design. Considering a rainfall event with RP of 25 years, Fig. 15 shows

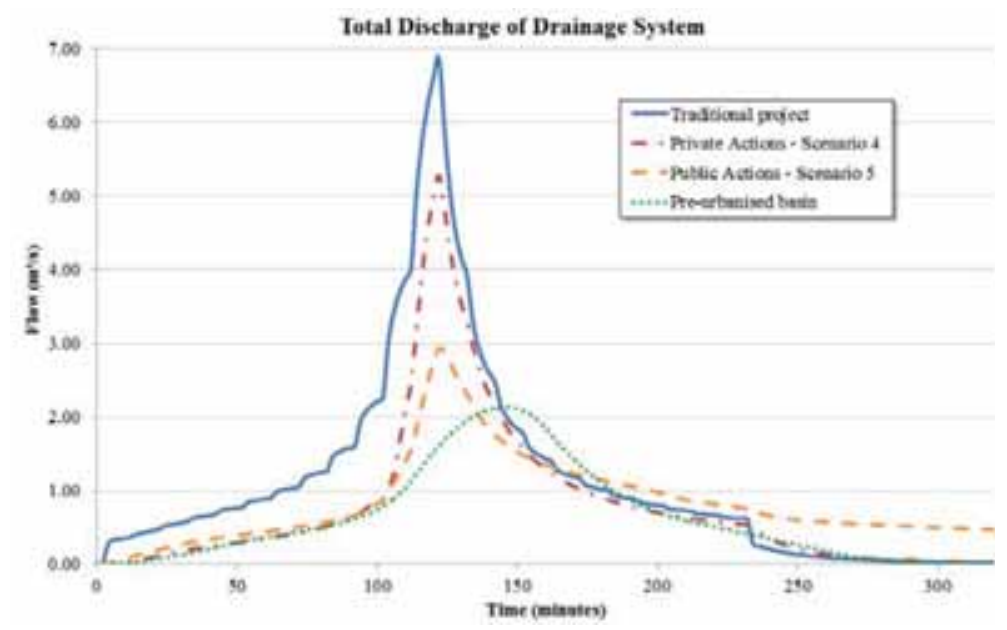

Figure 14: Total drainage outfall discharges, for the 10 years rainfall.

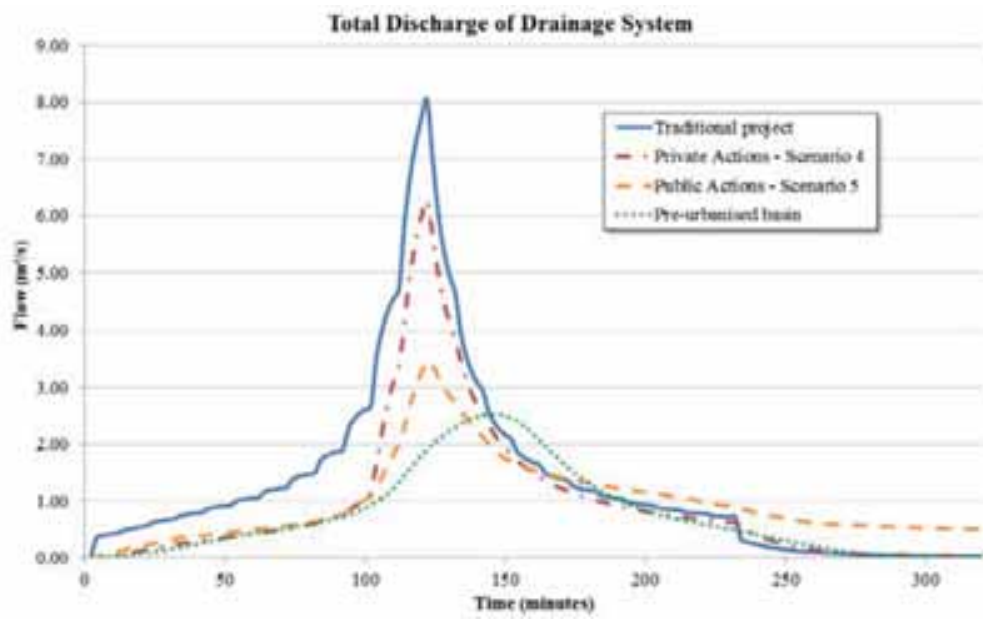

Figure 15: Total drainage outfall discharges, for the 25 years rainfall. 
the hydrographs related with Scenarios 4 and 5, compared with the traditional design and the preurbanisation condition. The magnitude of peak flow increased from $2.52 \mathrm{~m}^{3} / \mathrm{s}$ in the pre-urbanised scenario to $8.04 \mathrm{~m}^{3} / \mathrm{s}$ in the traditional design scenario.

Although neither private nor public actions were able to restore natural peak flow individually, both actions working together had their effects combined, and the final results showed that the discharge of the drainage system recovered. Figure 16 shows these results for a rainfall event with 10 years of RP. For this event, the drainage system in Scenario 6 had a maximum discharge of 1.94 $\mathrm{m}^{3} / \mathrm{s}$, or $9 \%$ lower than natural peak flow, while there still was a reduction in peak time. Furthermore, considering the traditional project, the difference in peak flow is $72 \%$ lower in Scenario 6. For the rainfall event with 25 years of RP, the effects of public and private actions were still effective, showing a maximum discharge of the drainage system slightly higher (9\%) than natural peak flow, with a value of $2.74 \mathrm{~m}^{3} / \mathrm{s}$ (Fig. 17).

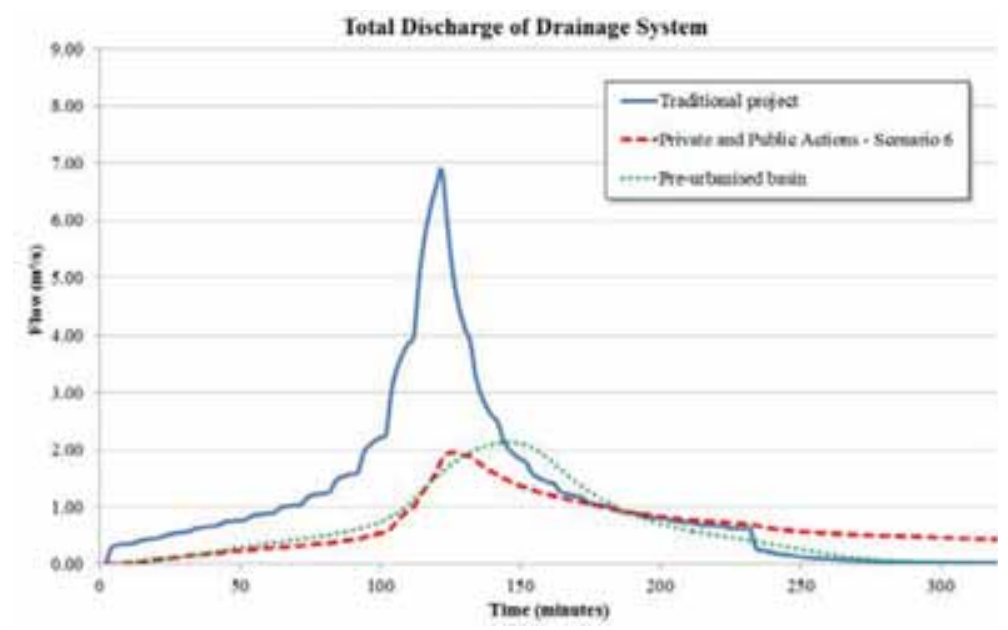

Figure 16: Total drainage outfall discharges, for the 10 years rainfall.

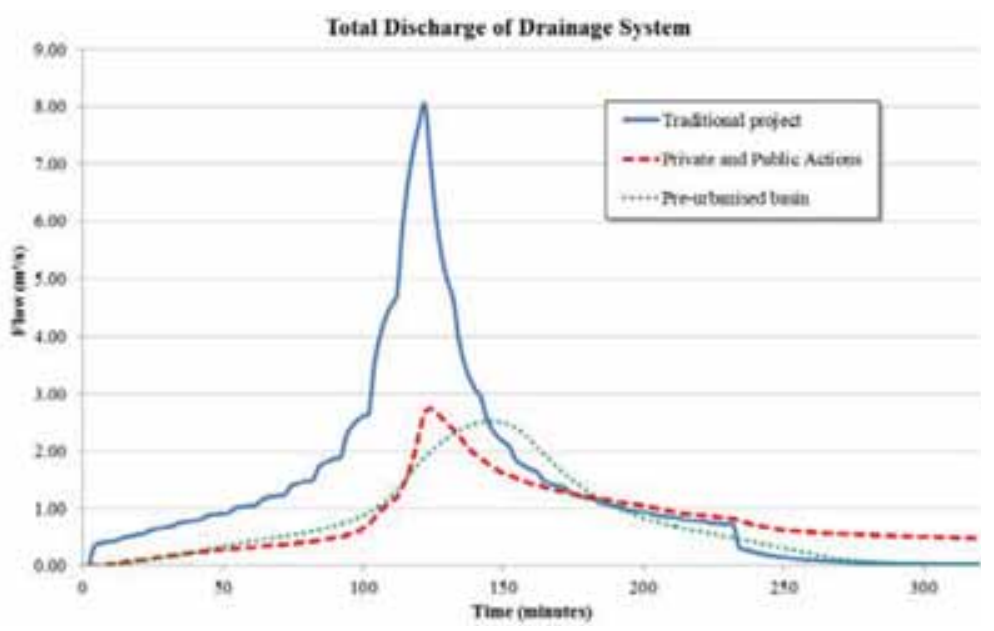

Figure 17: Total drainage outfall discharges, for the 25 years rainfall. 


\section{CONCLUDING REMARKS}

The influence of the city growth process on the urban water cycle and, consequently, on the drainage system is clear in the obtained results for this study. The urbanisation of a new housing subdivision in a developing area of Rio de Janeiro City would lead to an increase of three times in the generated discharges, when compared with the ones related with the natural landscape. This increase is very significant and it occurs even considering that the municipality limits the maximum impervious rates. The implementation of LID measures on the designed housing subdivision proposed in this study, as an alternative for new developments, produced very positive impacts when compared with traditional urban drainage systems. LID interventions were able to preserve and recover much of the storage capacity and the natural infiltration, reducing the impacts of urban growth on the hydrological cycle. Besides an improvement in the housing subdivision, landscaping was also possible with the use of green alleys and multifunctional landscapes.

One important aspect to be stressed, considering the simulated results for the case study, is that LID interventions become more effective if implemented intensively over the catchment, near the runoff generation sources, leading to the need of joint actions in public and private spaces. Generally, it tends to be easy to work in the public space, but private areas cover a significant portion of the watershed and should be included in the designed solution. The chosen set of measures, combining the use of garden lots, with infiltration and storage purposes, permeable pavements on sidewalks and temporary storage ponds in square and alleys, was able to control flood peaks. The pre-urbanisation values were approximately reproduced, both for the local and the basin scales, although peak times were not recovered. This context indicates the importance of private property owners' commitment in the urban flood control efforts. In fact, this combination complies with the sustainable urban drainage principles, regarding the necessity to construct a framework integrating social, technical and economic aspects.

\section{ACKNOWLEDGMENTS}

The authors acknowledge CNPq for the scholarships and FINEP for the support.

\section{REFERENCES}

[1] O’Driscoll, M., Clinton, S., Jefferson, A., Manda, A. \& McMillan, S., Urbanization effects on watershed hydrology and in-stream processes in the southern United States. Water, 2(3): pp. 605-648, 2010. doi: http://dx.doi.org/10.3390/w2030605

[2] Caputo, U., Moura, P. \& Nascimento, N., Evaluating the implementation of infiltration trenches in areas with consolidated urbanization: case of Belo Horizonte, Brazil. $12^{\text {th }}$ ICUD Conference, Porto Alegre, Brazil, 2011.

[3] Andoh, R.Y.G. \& Iwugo, K.O., Sustainable urban drainage systems: a UK perspective, 9th ICUD Conference, Portland, OR, USA, 2002.

[4] Baptista, M., Nascimento, N. \& Barraud, S., Compensatory Techniques on Urban Drainage. ABRH: Porto Alegre, Brazil, 2005 (in Portuguese).

[5] US EPA - United States Environmental Protection Agency. Low Impact Development A Literature Review. EPA-841-B-00-005. Office of Water: Washington, DC, 2000.

[6] France, R.L., Handbook of Water Sensitive Planning and Design. Lewis: Washington, DC, 2000.

[7] Coffman, L.S., Cheng, M., Weinstein, N. \& Clar, M. Low-impact development hydrologic analysis and design. Proceedings of the 25th Annual Conference on Water Resources Planning and Management. American Society of Civil Engineering: Chicago, IL, New York:, pp. 1-8, 1998. 
[8] Miguez, M.G., Mascarenhas, F.C.B. \& Magalhães, L.P.C., Multifunctional landscapes for urban flood control in developing countries. International Journal of Sustainable Development and Planning. 2(2), pp. 153-166, 2007. doi: http://dx.doi.org/10.2495/SDP-V2-N2-153-166

[9] Dietz, M.E., Low impact development practices: a review of current research and recommendations for future directions. Water, Air and Soil Pollution, 186(1e4), pp. 351-363, 2007.

[10] Hood, M.J., Clausen, J.C. \& Warner, G.S., Comparison of stormwater lag times for low impact and traditional residential development. Journal of the American Water Resources Association, 43(4), pp. 1036-1046, 2007. doi: http://dx.doi.org/10.1111/j.1752-1688.2007.00085.x

[11] Stahre, P., 15 Years Experiences of Sustainable Urban Storm Drainage in the City of Malmo, Sweden. World Water and Environmental Resources Congress: Alaska, 2005.

[12] Walsh, T. \& Pomeroy, C., Decentralization of LID (i.e. Municipal Rainwater Harvesting Program) for Reducing Stormwater Runoff. World Environmental and Water Resources Congress 2012: Crossing Boundaries, New Mexico, USA, 2012.

[13] Davis, A.L., Green engineering principles promote low impact development. Environ. Sci. Technol., 39, pp. 338A-344A, 2005.

[14] Fassman, E.A. \& Blackbourn, S., Urban runoff mitigation by a permeable pavement system over impermeable soils. J. Hydrol. Eng., 15, pp. 475-485, 2010. doi: http://dx.doi.org/10.1061/ (ASCE)HE.1943-5584.0000238

[15] Gregoire, B.G. \& Clausen, J.C., Effect of a modular extensive green roof on stormwater runoff and water quality. Ecol. Eng., 37, pp. 963-969, 2011. doi: http://dx.doi.org/10.1016/j.ecoleng.2011.02.004

[16] United States Department of Defense - USDoD, Unified Facilities Criteria (UFC) Design: Low Impact Development Manual. USDoD: USA, 2004.

[17] Ahiablame, L.M., Engel, B.A. \& Chaubey, I., Effectiveness of low impact development practices: literature review and suggestions for future research. Water, Air \& Soil Pollution, 223(7), pp. 4253-4273, 2012. doi: http://dx.doi.org/10.1007/s11270-012-1189-2

[18] WIT Transactions on Ecology and the Environment, Vol. 155, ( 2012 WIT Press doi: 10.2495/ SC120391. www.witpress.com, ISSN 1743-3541 (on-line). doi: http://dx.doi.org/10.2495/ SC120391

[19] Google Earth, www.google.com/earth.

[20] Mascarenhas, F.C.B., Toda, K., Miguez, M.G. \& Inoue, K., Flood Risk Simulation. WIT Press: Southampton, Boston, 436pp, 2005.

[21] Miguez, M.G., Flow cell mathematical model to urban catchments. D.Sc. Thesis, Universidade Federal do Rio de Janeiro, Rio de Janeiro, RJ, Brazil, 301pp, 2001 (in Portuguese). 